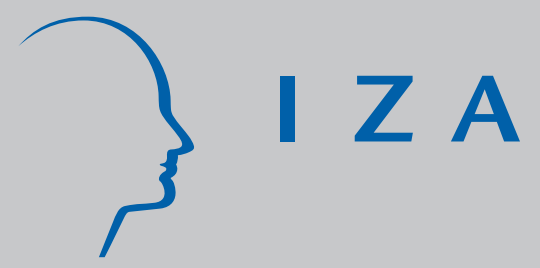

IZA DP No. 1126

Real Options Effects on Employment:

Does Exchange Rate Uncertainty

Matter for Aggregation?

Ansgar Belke

Matthias Göcke

April 2004 


\title{
Real Options Effects on Employment: Does Exchange Rate Uncertainty Matter for Aggregation?
}

\author{
Ansgar Belke \\ University of Hohenheim \\ and IZA Bonn \\ Matthias Göcke \\ University of Münster
}

\section{Discussion Paper No. 1126 \\ April 2004}

IZA
P.O. Box 7240
53072 Bonn
Germany

Phone: +49-228-3894-0

Fax: +49-228-3894-180

Email: iza@iza.org

\begin{abstract}
Any opinions expressed here are those of the author(s) and not those of the institute. Research disseminated by IZA may include views on policy, but the institute itself takes no institutional policy positions.
\end{abstract}

The Institute for the Study of Labor (IZA) in Bonn is a local and virtual international research center and a place of communication between science, politics and business. IZA is an independent nonprofit company supported by Deutsche Post World Net. The center is associated with the University of Bonn and offers a stimulating research environment through its research networks, research support, and visitors and doctoral programs. IZA engages in (i) original and internationally competitive research in all fields of labor economics, (ii) development of policy concepts, and (iii) dissemination of research results and concepts to the interested public.

IZA Discussion Papers often represent preliminary work and are circulated to encourage discussion. Citation of such a paper should account for its provisional character. A revised version may be available on the IZA website (www.iza.org) or directly from the author. 


\begin{abstract}

\section{Real Options Effects on Employment: Does Exchange Rate Uncertainty Matter for Aggregation?*}

In a baseline micro model a band of inaction due to hiring- and firing-costs is widened by option value effects of exchange rate uncertainty. Based on this micro foundation an aggregation approach is presented. Under uncertainty, intervals of weak response to exchange rate reversals (called 'play' areas) are introduced on the macro-level. 'Spurts' in new employment or firing may occur after an initially weak response. Since these mechanisms may apply to other "investment" cases where the aggregation of microeconomic real options effects under uncertainty are relevant, they may even be of a more general interest.
\end{abstract}

JEL Classification: J23, F41, D81

Keywords: aggregation, employment hysteresis, exchange rate uncertainty, real options

Corresponding author:

Ansgar Belke

Institut für VWL insb. Außenwirtschaft

Universität Hohenheim

70593 Stuttgart

Germany

Tel.: +497114593246

Email: belke@uni-hohenheim.de

\footnotetext{
* This paper benefited from valuable comments by an anonymous referee and by participants of the Annual Conference of the German Economic Society, Mainz/Germany, the International Conference of the Society for Computational Economics, Boston/USA, the Annual Conference of the European Association of Labour Economists, Regensburg/Germany, and the Annual Congress of the European Economic Association, Santiago de Compostela/Spain. The usual caveats apply. This paper is forthcoming in German Economic Review.
} 


\title{
Real Options Effects on Employment: Does Exchange Rate Uncertainty Matter for Aggregation?
}

\author{
by Ansgar Belke and Matthias Göcke
}

\section{Introduction}

The usual presumption of EMU proponents has been that lowering exchange rate volatility promotes foreign trade. However, macroeconomic empirical evidence is far from conclusive in that respect (e.g. Côté, 1994). The possibility that exchange rate uncertainty could have an impact on labour market performance or at least on the relation between employment and its determinants has not been considered so far (Belke and Gros, 2001). The lack of a theoretical and empirical literature on the effect of exchange rate variability on employment is striking in view of the high policy relevance of the question (Dornbusch, 1987) and in view of the fact that there is considerable literature on the link between investment and uncertainty (Cushman, 1985, Darby et al., 1998). Given the high hiring and firing costs affecting European labour markets (Bentolila and Bertola, 1990, Saint-Paul, 1996) one would assume that the same arguments that underpin the presumed effect of volatility on investment should also apply to exchange rate volatility and employment. But given the weak results concerning the link between exchange rate volatility and trade, the prior of many economists seemed to be that exchange rate variability is not important and that there should be no link between exchange rate variability and (un)employment.

Côté (1994) and de Grauwe and Skudelny (1997) show that the empirical puzzle concerning the impact of exchange rate uncertainty and foreign trade might have been due to the methods chosen so far. In the light of their arguments (but relying on a totally different theoretical approach) this paper argues that - on a micro level - the absence of evidence of a strong impact of exchange rate variability on the volume of trade is due to neglecting a "band of inaction" of export activity based on sunk costs. Its impacts are amplified by volatility-induced uncertainty. This export inactivity band spills over to labour markets leading to stronger 
persistence in (un)employment. ${ }^{1}$ In order to solve the empirical puzzle, the micro approach has to be transferred to the macro-level.

A macro interpretation of micro hysteresis and of uncertainty impacts on 'investment' decisions cannot be performed in a straightforward way, since different firms have different 'investment' thresholds. For this reason, we pay special attention to the problem of aggregation. $^{2}$ The examination of the persistent effects of only temporary exchange rate shocks on employment behaviour of single firms and on overall employment is conducted based on an aggregation approach, developed by Krasnosel'skii and Pokrovskii (1989) and Mayergoyz (1986) and introduced to economics by Amable et al. (1991, 1995) and Cross (1994). This approach stresses the differences between hysteretic effects on the micro and on the macro level and the consequences of aggregation (under certainty): while at the micro level certain threshold values of the input variable have to be passed in order to produce branch-to-branch-transitions (i.e. shifts in the input-output relation), at the macro level small changes in the input variable can yield long-lasting effects. ${ }^{3}$ What is up to now not wellknown in the literature is how the introduction of uncertainty influences the transition from micro to macro behaviour. In this contribution we show that under uncertainty areas of nonreaction - corresponding to mechanical play the so-called 'play'-area - have to be considered even at the macro level. Thus, similarities of macro relations ['play'] to micro behaviour [band of inaction] are enhanced by uncertainty. ${ }^{4}$ The first result of the paper is that persistent aggregate (employment) effects do not necessarily result from small changes in the forcing

1 For a theoretical treatment see Belke and Göcke (1999).

2 For aggregation problems in the presence of underlying non-linear micro relations see van Garderen, Lee and Pesaran (1997). Generally, the aggregation is regarded as especially complicated in this case. Since we impose very stringent restrictions on the shape of the non-linearity, we are able to derive a definite macro behaviour.

3 In this context, the terms 'input' and 'output' are used in a mathematical or physical sense ('input-output transducer'). The macro form is called 'strong' hysteresis (Amable et al., 1991, 1994, Cross, 1994). Another recent strand of literature deals with models which are more general with respect to the non-linearities at the micro level than the one presented here. See e.g. Caballero, Engel and Haltiwanger (1997). These models explain aggregate employment dynamics, but dispense with an explicit derivation of an aggregation mechanism over heterogeneous firms.

4 For an overview of the variety of uses of the term 'hysteresis' in economics for different path-dependent phenomena ranging from 'band of inaction', 'play' to 'strong hysteresis' especially compared to the approximation of hysteresis via unit (zero) roots in difference (differential) equations see Amable et a. (1994) and Göcke (2002). 
(labour market) variables, as far as the changes occur inside the play-area. However, as far as changes go beyond the play-area, suddenly strong reactions (and persistence effects) will occur. With this, we theoretically capture the 'spurts' commonly observed in aggregate hiring / firing or investment decisions explicitly based on an aggregation approach for heterogeneous firms. ${ }^{5}$

The outline of the paper is as follows. Sections 2 to 4 give a repetitive introduction to aspects of hysteresis well known in the literature: In section 2 the baseline micro model of employment hysteresis under certainty is described. Section 3 deals with the aggregation approach under certainty. Modifications on the micro level necessitated by uncertainty are focused on in section 4. Section 5 "adds the beef" to our paper: As the main contribution a method to solve the problem of aggregation from micro to total economy employment under uncertainty is presented. Section 6 concludes.

\section{The micro model under certainty}

We consider an extremely simple model of an exporting firm which has been active or passive in a foreign market in the past. Depending on its past state of activity this firm might either retain activity or exit (if it has been active in the past) respectively remain passive or enter the foreign market (if it has been passive). If a previously inactive firm enters the market, it has to bear entry costs, i.e. costs of hiring new labour. These expenditures cannot be regained and are therefore ex-post treated as sunk costs. Thus entering (leaving) can be compared with an investment (disinvestment) project.

The firm $\mathrm{j}$ is assumed to be a price taker in the foreign and in the currency market. It produces one unit ${ }^{6}$ of a final product using $\mathrm{a}_{\mathrm{j}}$ units of labour, with the wage $\mathrm{w}$ being the price of labour, i.e. variable costs are $\mathrm{w} \cdot \mathrm{a}_{\mathrm{j}}$. Selling on the foreign market, the firm receives the price $\mathrm{p}^{*}$. The

5 For an (empirical) macro analysis of 'spurts' in investment implicitly based on micro (i.e. threshold) models see Darby et al. (1998), pp. 24 ff.

6 If an institutional firm is imagined to be divided into single production units, every unit is represented here individually. By this form of (fictitious) dis-aggregation a totally new erection as well as an enlargement of employment by an institutional firm can be included. 
gross profit (in domestic currency) on sales in the foreign market, without consideration of hiring and firing costs, is: ${ }^{7}$

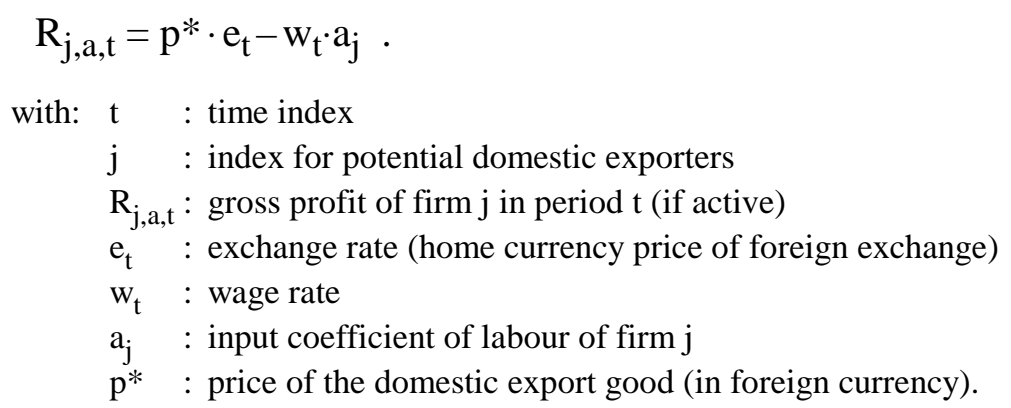

We feel justified to ascribe the revenue volatility solely to exchange rate volatility, since it is well-known that short-term volatility of exchange rates exceeds the variability of prices, wages and productivity by far. ${ }^{8}$ We assume $\mathrm{w}_{\mathrm{t}}=\mathrm{w}$ and $\mathrm{a}_{\mathrm{j}}$ to be constant and normalise $\mathrm{p}^{*}$ to unity. As a consequence, the exporters are forced to bear unit revenue changes (in their own currency) proportionally to the exchange rate changes. A weaker form of the results of our model stays valid, if $\mathrm{p}^{*}$ changes under-proportionally compared with the exchange rate. The same logic can be applied to import-competing firms, whose revenues are influenced by the exchange rate as well. Using this simplification, the gross profit of firm $\mathrm{j}$ follows as:

$$
\mathrm{R}_{\mathrm{j}, \mathrm{a}, \mathrm{t}}=\mathrm{e}_{\mathrm{t}}-\mathrm{w} \cdot \mathrm{a}_{\mathrm{j}} \quad \text { (if active), otherwise } \mathrm{R}_{\mathrm{j}, \mathrm{p}, \mathrm{t}}=0 \quad \text { (if passive) . }
$$

It is assumed that the hiring costs $\mathrm{H}_{\mathrm{j}}$ (including training costs) must be spent at the moment the entry is executed, and the firm has to pay firing costs $F_{j}$ at the time it leaves the market (e.g. severance pay). If it later decides to re-enter the market, the entire hiring costs must be repaid. If the firm is inactive for only one period, the staff must be completely re-set up and the hiring costs must be paid anew. Since switching the state of activity leads to a complete depreciation of hiring respectively firing costs, $H_{j}$ and $F_{j}$ have to be regarded as sunk costs ex post. The decision whether the firm should sell abroad or not, is reached by a comparison of the expected present values of the returns with or without being active in the decision period t.

7 For a related model see Baldwin and Krugman (1989), p. 638 and Göcke (1994). Using an index j indicates heterogeneity between firms.

$8 \quad$ See e.g. Darby et al. (1998), pp. 1 f., Krugman (1989), p. 64. 
A firm $\mathrm{j}$ which has been active in the preceding period and will continue its activity will gain the period t revenue $R_{j, a, t}$. The discount factor is defined as $\delta=1 /(1+i)$ with interest rate $i$. Since it expects the same revenue for the whole infinite future the present value of annuity due of continuing activity is $\left(\mathrm{e}-\mathrm{w} \cdot \mathrm{a}_{\mathrm{j}}\right) /(1-\delta)$, which has to be compared to the present value of an instantaneous exit, i.e. firing costs $\left(-\mathrm{F}_{\mathrm{j}}\right)$. Equating both leads to an exit trigger exchange rate value $\beta_{\mathrm{j}}$ for switching from employment to inactivity:

$$
\beta_{j}=e_{j, \text { exit }}^{c}=w \cdot a_{j}-(1-\delta) \cdot F_{j} \quad \text { with: exit if } e_{t}<\beta_{j} .
$$

Therefore, the unit revenue e has to cover at least the wage costs $w \cdot a_{j}$ less the interest costs of exit. Hence, due to the sunk firing costs the price floor is below variable costs.

A previously non-active firm earns neither current nor future profits if it remains passive. If it enters the market and hires new employees it has to pay extra hiring costs $\mathrm{H}_{\mathrm{j}}$ to be able to earn current and future profits: $-\mathrm{H}_{\mathrm{j}}+\left(\mathrm{e}-\mathrm{w} \cdot \mathrm{a}_{\mathrm{j}}\right) /(1-\delta)$. With this, the entry trigger $\alpha_{\mathrm{j}}$ is:

$$
\alpha_{j}=e_{j, \text { entry }}^{c}=w \cdot a_{j}+(1-\delta) \cdot H_{j} \quad \text { with: entry if } e_{t}>\alpha_{j} \quad \text { and } \alpha_{j}>\beta_{j} \text {. }
$$

Due to the sunk hiring costs, the necessary unit revenue is larger than the variable costs. Combining both trigger values, a 'band of inaction' results (Fig. 1). The latter implies that the current realisation of the exchange rate is not sufficient to determine the current state of the firm's activity. Depending on the past, the relationship between input variable (exchange rate) and output variable (employment) is represented by different curves. ${ }^{9}$ In order to select one of the multiple equilibria, the history of activity has to be regarded. In the case of micro hysteresis nonlinearity has a very simple form: there exist only two 'branches' with a discontinuous branch-to-branch-transition when certain threshold-values are passed.

\footnotetext{
9 Remember: the terms 'input' and 'output' are used in a mathematical or physical sense.
} 
Fig. 1: Micro hysteresis for a single-unit firm $\mathrm{j}$ under certainty

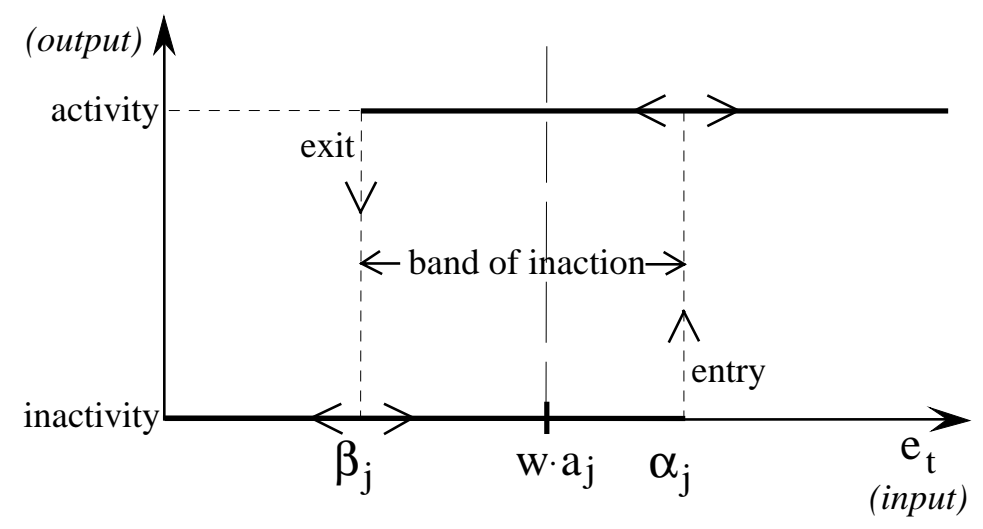

\section{Macro level: an aggregation approach}

In this section we describe a procedure which allows an aggregation of heterogeneous single firms with an employment behaviour characterised by a micro hysteresis loop, resulting in a continuous macro loop of overall employment (see Amable et al., 1991, 1995, Cross, 1994, and Göcke, 1994). Every potentially active firm is characterised by its $\alpha_{j} / \beta_{j}$-set. Since $\alpha_{j} \geq \beta_{j}$, all $\alpha / \beta$-points are located in the triangle area $\mathrm{T}$ above the $45^{\circ}$-line. The aggregation is done without any serious restriction of heterogeneity in the cost structure (concerning $\mathrm{H}_{j}, \mathrm{~F}_{\mathrm{j}}$ and $\mathrm{a}_{\mathrm{j}}$ ) between the firms. Points on the $45^{\circ}$-line describe non-hysteretic employers $\left(\mathrm{H}_{\mathrm{j}}, \mathrm{F}_{\mathrm{j}}=0 \Rightarrow\right.$ $\alpha=\beta$ ), the distance from the origin given by $w \cdot a_{j}$. For points above the line there is micro hysteresis in employment, the distance from the $(\alpha=\beta)$-line measured in north west direction determined by $\mathrm{H}_{\mathrm{j}}$ and $\mathrm{F}_{\mathrm{j}}$.

In order to prevent extensive assumptions concerning the past exchange rate development, the exchange rate $\mathrm{e}=0$ is assumed as an initial level. Therefore, no firm is active initially. Starting from $\mathrm{e}=0$ the exchange rate rises, resulting in hiring by firms with the lowest costs (and the lowest entry rate $\alpha_{j}$ ). ${ }^{10}$ Hence, overall employment increases, as traced in Fig. 2 (a). ${ }^{11}$ The triangle $\mathrm{T}$ is divided into two shares: $\mathrm{S}_{\mathrm{t}}^{+}$(including all active firms) and $\mathrm{S}_{\mathrm{t}}^{-}$(including all inactive firms). For increasing exchange rates, the share $S_{t}^{+}$expands while $S_{t}^{-}$diminishes. The

10 The exchange rate $\mathrm{e}=0$ has not to be understood in a strict way: The exchange rates could also be stated in a standardised form with $\mathrm{e}=0$ as the rate that induces an exit of all firms. See Amable et al. (1991), p. 10.

11 The increase in overall employment takes place on the lowest branch (path OAB in Fig. 4). 
firms with a changing state of activity are described by the $\alpha / \beta$-points in the hatched area. For rising rates, the $\mathrm{S}_{\mathrm{t}}^{+}$-expansion is indicated by an upward shift of the horizontal borderline.

Fig. 2: Active firms under a volatile exchange rate
(a) ascending exchange rate
(b) descending exchange rate

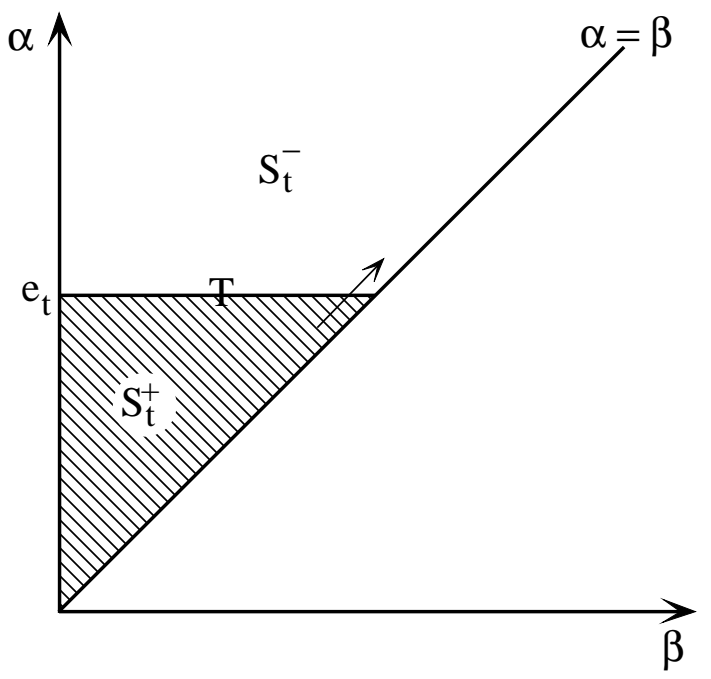

(c) again increasing exchange rate

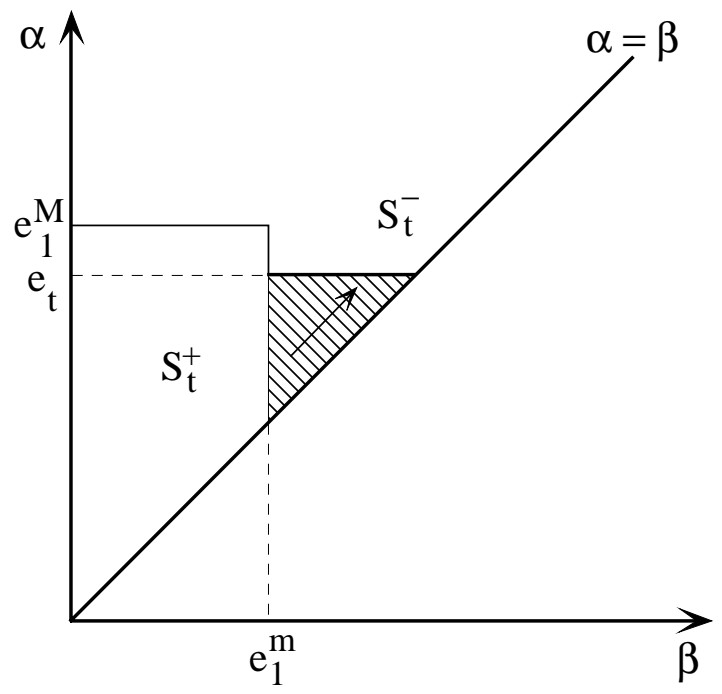

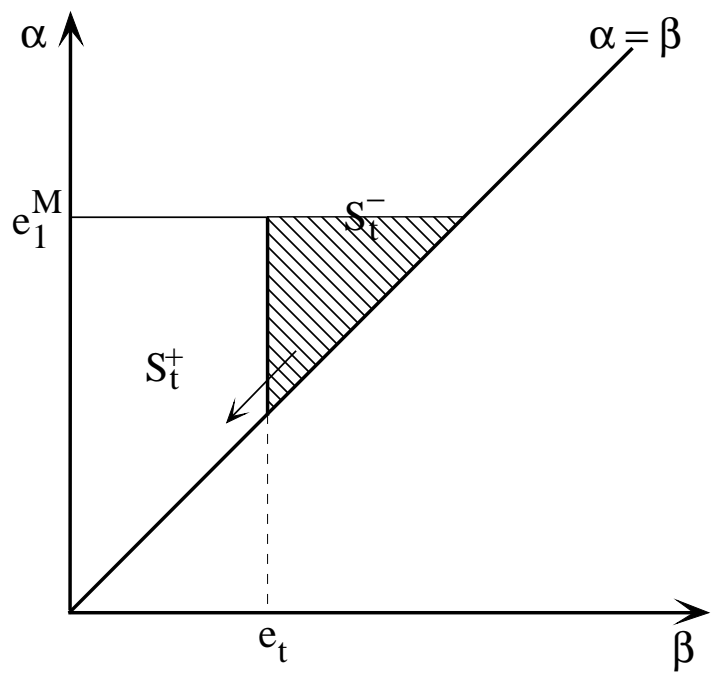

(d) again decreasing exchange rate

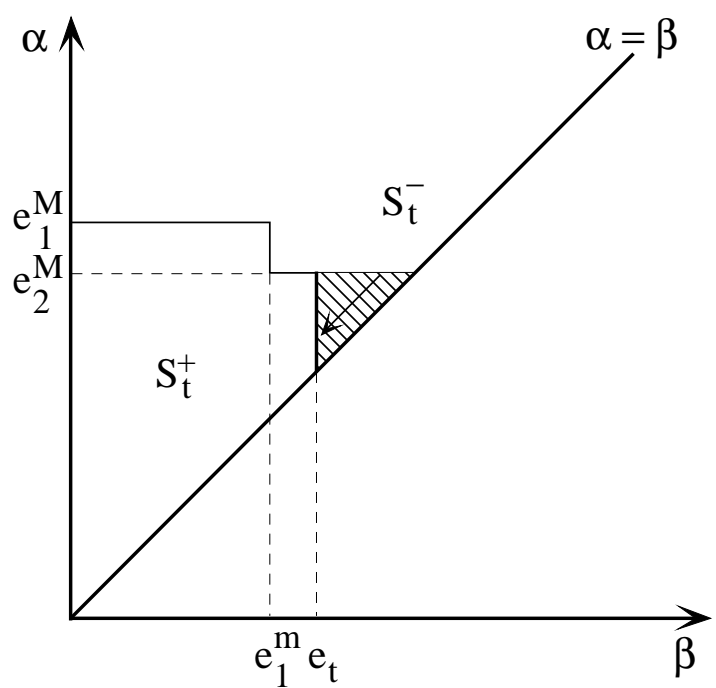

Source: Following Amable et al. (1991), Figure 3 and 4.

In Fig. 2 (b) a subsequent decrease in the exchange rate is traced: $e_{t}$ falls from the highest value, the (local) maximum $\mathrm{e}_{1}^{\mathrm{M}}$. Therefore, $\mathrm{S}_{\mathrm{t}}^{+}$decreases, since firms, which recently hired new employees, now leave the market when the exchange rate falls below their exit rate $\beta_{\mathrm{j}}$. For decreasing exchange rates, the activity changes (hatched area) are illustrated by a left vertical shift of the $\mathrm{S}_{\mathrm{t}}^{-}-\mathrm{S}_{\mathrm{t}}^{+}$-borderline. (The corresponding macro reaction is path $\mathrm{BC}$ in Fig. 4.) 
If the exchange rate rises again, after reaching the local minimum $\mathrm{e}_{1}^{\mathrm{m}}$ (the lowest input level apart from the initial rate $\mathrm{e}_{0}^{\mathrm{m}}=0$ ), $\mathrm{S}_{\mathrm{t}}^{+}$expands again. This is depicted in Fig. 2 (c) once again by an upward shift of the right-horizontal part of the borderline. ${ }^{12}$ The result of the subsequent shifts is a "staircase-shape" of the border between the two parts of T. If the recently reached (local) maximum is lower than the highest maximum $\mathrm{e}_{1}^{\mathrm{M}}$, a staircase step in the borderline remains characterised by the coordinates $\left(\alpha=\mathrm{e}_{1}^{\mathrm{M}} / \beta=\mathrm{e}_{1}^{\mathrm{m}}\right)$. If the exchange rate would have continued to increase and would have passed the original maximum, the $\alpha$-coordinate of the "e ${ }_{1}^{\mathrm{M}}$-step" would have been "erased" and would have been replaced by the "new" $\mathrm{e}_{1}^{\mathrm{M}} \cdot 13$ However, if (as traced in Fig. 2 (c)) the new local maximum is lower than the "old" $\mathrm{e}_{1}^{\mathrm{M}}$, the maximum $\mathrm{e}_{1}^{\mathrm{M}}$ remains and the new local maximum becomes the second highest, and is consequently labelled $\mathrm{e}_{2}^{\mathrm{M}}$.

Fig. 2 (d) illustrates a later decreasing exchange rate. The borderline is changed by a shift to the left of the lower vertical part (corresponding to DE in Fig. 4). If $e_{t}$ does not fall below $e_{1}^{m}$ with the new local minimum (disregarding the initial level) the second lowest minimum is given, labelled $e_{2}^{m}$. If the input were to fall under the "old" $e_{1}^{m}$, the $\beta$-coordinate of the corresponding staircase-step would be eliminated and the new local minimum would be (the "new") $\mathrm{e}_{1}^{\mathrm{m} \cdot{ }^{14}}$ If subsequent local maxima and minima are not as "extreme" as the preceding extrema, a new corner in the staircase border is created. On the other hand, local maxima which are higher than preceding maxima will erase the $\alpha$-coordinate of the corresponding corners; subsequent local minima erase the $\beta$-coordinate of corners corresponding to higher preceding minima (Amable et al., 1991, pp. 11 ff.). For a given exchange rate path, the remaining maxima are ordered by descending size and the remaining minima by ascending size; a sequence of local maxima $e_{i}^{M}$ and local minima $e_{i}^{m}$ results $(i=1, \ldots, p)$. The $\alpha / \beta$ coordinates of the outward corners of the staircase $\mathrm{S}_{\mathrm{t}}^{+}-\mathrm{S}_{\mathrm{t}}^{-}$-borderline are given by the pairs $\left(\alpha=e_{i}^{M}\right.$ and $\left.\beta=e_{i}^{m}\right)$. An illustration of the staircase borderline is drawn in Fig. 3 (a) for rising and in Fig. 3 (b) for falling exchange rates.

\footnotetext{
12 The resulting macro reaction is depicted as path CD in Fig. 4.

13 For the erasing property see Mayergoyz (1986), p. 605.

14 Consequently, starting with $\mathrm{e}=0$ erases all steps and so the whole influence of the past.
} 
Fig. 3: Active firms when the exchange rate

(a) rises

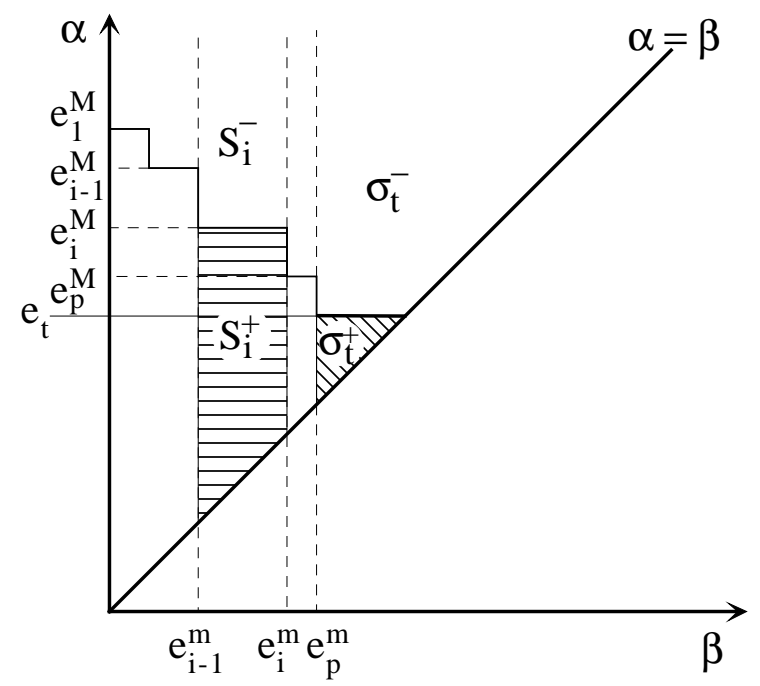

(b) decreases

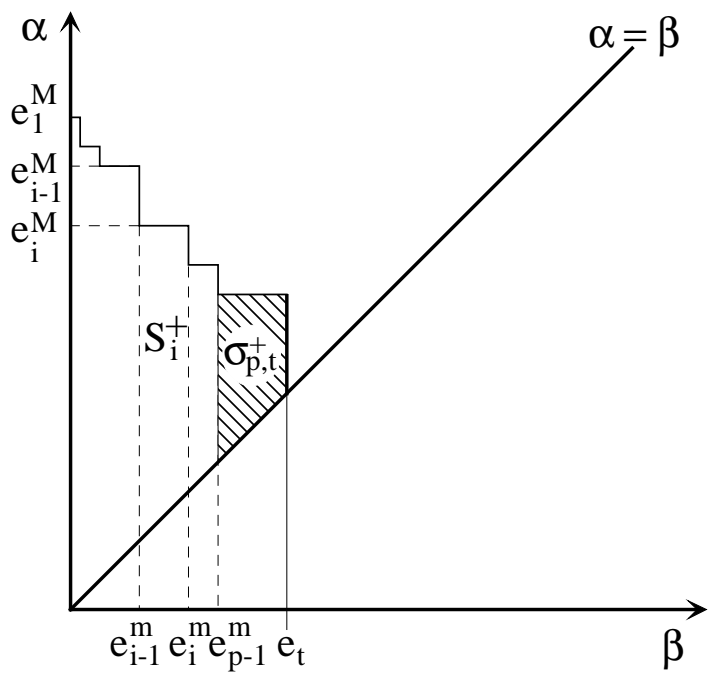

Source: Following Amable et al. (1991), Figures 5 and 8.

For ascending exchange rates the area $\mathrm{S}_{\mathrm{t}}^{+}$(including all active firms) can be divided into two partial areas $\left(\sum_{\mathrm{i}}^{\mathrm{p}} \mathrm{S}_{\mathrm{i}}^{+}\right.$and $\left.\sigma_{\mathrm{t}}^{+}\right)$. Path-dependence is captured by the influence of the past input extrema on the area of the active (i.e. employing) firms. When the exchange rate decreases, the area $S_{t}^{+}$is changed by shifts to the left of the lower right vertical part of the border. Only $\sigma_{\mathrm{p}, \mathrm{t}}^{+}$is directly influenced by $\mathrm{e}_{\mathrm{t}}$, while $\sum_{\mathrm{i}}^{\mathrm{p}-1} S_{\mathrm{i}}^{+}$depends on past extrema. $\sigma_{\mathrm{p}, \mathrm{t}}^{+}$diminishes with decreasing $e_{t}$, until the stage corresponding to the (highest not yet not-erased) minimum $e_{p-1}^{m}$ is erased and the order $(\mathrm{p}-1)$ of $\sum_{i}^{\mathrm{p}-1} S_{i}^{+}$is reduced by one.

Thus, the basic formal structure of the results for employment in the cases of rising and falling exchange rates is similar: an important constant term that is determined by the past extrema stands aside a term that is influenced by the current exchange rate $e_{t}$. The relations that are valid for the current exchange rate have been shifted by past input extrema. Consequently, every reversal in the direction of the exchange rate input path leads to a structural break in the exchange rate-employment (i.e. 'input-output') relation.

In the case of micro hysteresis only two branches are possible. A jump between these two (not continuously linked) 'branches' only occurs with the passing of certain threshold values. The continuous macro loop (Fig. 4) results from aggregation over a bulk of heterogeneous micro elements. Due to the lack of thresholds and to the fact that the path-dependence is captured by 
the local input variable extrema even small changes in the exchange rate can have durable effects on employment. ${ }^{15}$

Fig. 4: The macroeconomic exchange rate-employment hysteresis loop

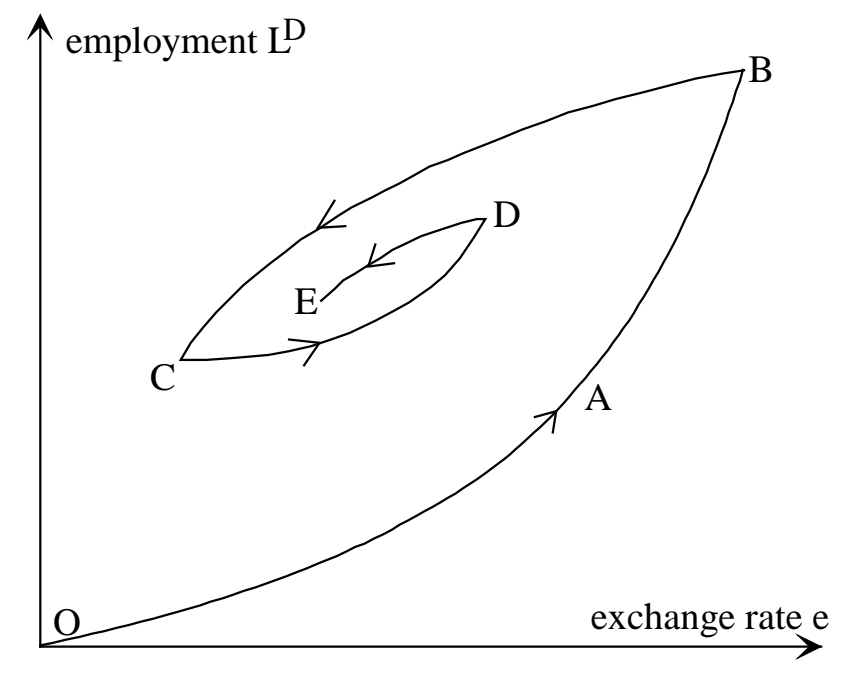

The distribution of the heterogeneous firms in the $\alpha, \beta$-space is important for the result of the analysis. A continuous distribution of the firms in the $\alpha, \beta$-space results in continuous macroeconomic loops in Fig. 4. The exact density of the $\alpha_{j}, \beta_{j}$-distribution will solely determine the curvature of the branches. The more all firms are clustered in a specific area (i.e. the more homogenous the firms are) the more curved are the branches. In the borderline case of a multiplicity of similar homogenous firms the macro-loop will degenerate to a loop of the form as depicted in Fig. 1 for a single firm.

\section{The micro model under one-off uncertainty and the possibility of waiting}

Uncertainty generates an option value of waiting, and therefore introduces a bias in favour of a "wait-and-see"-strategy. Since the firm's employment decision can be understood as an irreversible investment, we follow a real option approach. The firm's employment opportunity corresponds to a call option that gives the firm the right to employ (invest), hiring costs being the exercise price of the option, and to obtain a 'project'. The option itself is valuable, and

15 See Mayergoyz (1986) and Amable et al. (1991), p. 2, pp. 9 and p. 15. For a detailed mathematical analysis of various forms of hysteresis see Krasnosel'skii and Pokrovskii (1989) and Brokate and Sprekels (1996). 
exercising the employment investment "kills" the option. Analogously, disinvestment (firing) can be interpreted as a put option.

We analyse the effects of an expected future stochastic one-time shock on the band of inaction. However, assuming a risk-neutral firm, we abstract from risk-aversion. Focusing on employment impacts of uncertainty, we take up an idea originally proposed by Dornbusch (1987), pp. 8 f., Dixit (1989), p. 624, fn. 3, Bentolila and Bertola (1990), and Pindyck (1991), p. 1111. Option price effects are modelled in a technically sophisticated way in these references. Since we focus on the aggregation problem, we model micro uncertainty effects as simple as possible (based on the model by Belke and Göcke, 1999). However, the basic structure and the main micro effects of uncertainty are left unchanged compared to the cited references.

We suppose a non-recurring single stochastic change in the exchange rate, which can be either positive $(+\varepsilon)$ or negative $(-\varepsilon)$ (with $\varepsilon \geq 0$, mean preserving spread). For simplicity reasons, both realisations of the change $\varepsilon$ are presumed to have a probability of $1 / 2: e_{t+1}=e_{t} \pm \varepsilon$ and $E_{t}\left(e_{t+1}\right)=e_{t}$. From period $t+1$ on, the firm will decide under certainty again. Thus, the trigger exchange rate value under certainty ("c-trigger") as derived above will become valid again. The stochastic change between $t$ and $t+1$ leads to a widening of the band of inaction due to the possibility of a "wait-and-see"-strategy. Under certainty, the relevant alternative strategies are to enter or not for a previously inactive firm respectively to exit or not for a formerly active firm. Under uncertainty and the feasibility to delay an investment, a third alternative has to be taken into account: the option to wait and to meet the respective decision (i.e. entry or exit) in the future. The option to employ in the future is valuable because the future value of the 'asset' obtained by employment is uncertain. If its value will decrease, the firm will not need to employ and will only lose what it will have spent to keep the employment opportunity. This limits the risk downwards and with this generates the inherent value of the option.

Under uncertainty a previously active (i.e. employing) firm has to decide whether to leave the market now or to stay active, including the option to leave later. It may appear advantageous for the firm to bear temporary period $t$ losses, if there is a possibility of future gains. In this 
case the firm can avoid additional exit costs. ${ }^{16}$ On the one hand, the firm anticipates the possibility of future gains if the future exchange rate turns out to be favourable $(+\varepsilon)$. On the other hand, the firm foresees that it can avoid future losses if the exchange rate change will be negative $(-\varepsilon)$ with a later exit in $t+1$.

The expected present value of the wait-and-see strategy in period $t$ is defined as the probability-weighted average of the present values of both $\varepsilon$-realisations. Waiting implies a period t profit of $\mathrm{e}-\mathrm{w} \cdot \mathrm{a}_{\mathrm{j}}$. Conditional on the $(-\varepsilon)$-realisation, the firm will use its option to leave in $\mathrm{t}+1$ causing discounted firing costs $\delta \cdot \mathrm{F}_{\mathrm{j}}$. In the case of the favourable $(+\varepsilon)$-realisation the firm will stay and earn annuity value $\delta \cdot\left(e+\varepsilon-w \cdot a_{j}\right) /(1-\delta)$. Combining both, the expected present value of the wait-and-see strategy is:

$$
\mathrm{E}_{\mathrm{t}}\left(\mathrm{V}_{\mathrm{j}, \mathrm{t}}^{\mathrm{wait}}\right)=\mathrm{e}-\mathrm{w} \cdot \mathrm{a}_{\mathrm{j}}-\frac{1}{2} \cdot \delta \cdot \mathrm{F}_{\mathrm{j}}+\frac{1}{2} \cdot \delta \cdot \frac{\mathrm{e}+\varepsilon-\mathrm{w} \cdot \mathrm{a}_{\mathrm{j}}}{1-\delta}
$$

The present value of an immediate exit is simply determined by firing costs: $E_{t}\left(V_{j, t}^{\text {exit }}\right)=-F_{j}$. Hence, the firm is indifferent between exit in $t$ and 'wait-and-see' if $E_{t}\left(V_{j, t}^{\text {exit }}\right)=E_{t}\left(V_{j, t}^{\text {wait }}\right)$. As a consequence, the $u$-exit-trigger follows (with exit for $e_{t}<e_{j, e x i t}^{u}$ ):

$$
\mathrm{e}_{\mathrm{j}, \mathrm{exit}}^{\mathrm{u}}=\mathrm{w} \cdot \mathrm{a}_{\mathrm{j}}-(1-\delta) \cdot \mathrm{F}_{\mathrm{j}}-\frac{\delta \cdot \varepsilon}{2-\delta}=\mathrm{e}_{\mathrm{j}, \mathrm{exit}}^{\mathrm{c}}-\frac{\delta \cdot \varepsilon}{2-\delta}=\mathrm{e}_{\mathrm{j}, \mathrm{exit}}^{\mathrm{c}}-\frac{\varepsilon}{1+2 \mathrm{i}}
$$

A previously inactive firm has to decide whether to enter the market now or to stay passive, including the option to enter later. The firm anticipates the possibility of internalising future gains by an entry in $t+1$ if the future exchange rate turns out to be favourable $(+\varepsilon)$. Besides, the firm foresees that it can avoid future losses if the exchange rate change will be negative $(-\varepsilon)$ by staying passive. Waiting and staying inactive implies zero profits in t. Conditional on a $(+\varepsilon)$-realisation, the firm will use its option to enter in $t+1$ causing discounted hiring costs $\delta \cdot \mathrm{H}_{\mathrm{j}}$, gaining an annuity value of $\delta \cdot\left(\mathrm{e}+\varepsilon-\mathrm{w} \cdot \mathrm{a}_{\mathrm{j}}\right) /(1-\delta)$. For a $(-\varepsilon)$-realisation the firm will remain passive. Consequently, the expected present value of the wait-and-see strategy for a

16 We abstract from a later re-entry (and analogously from a later re-exit by a previously inactive firm), and therefore neglect re-entry (re-exit) costs. For a more detailed presentation of the micro framework under uncertainty and for a simultaneous consideration of exit and re-entry (entry and re-exit) options see Belke and Göcke (1999). 
previously inactive firm is given by $\mathrm{E}_{\mathrm{t}}\left(\mathrm{V}_{\mathrm{j}, \mathrm{t}}^{\text {wait }}\right)$ in eq. (7). The expected present value of an immediate entry (without a re-exit) is $\mathrm{E}_{\mathrm{t}}\left(\mathrm{V}_{\mathrm{j}, \mathrm{t}}^{\mathrm{entry}}\right)$ :

$$
\mathrm{E}_{\mathrm{t}}\left(\mathrm{V}_{\mathrm{j}, \mathrm{t}}^{\mathrm{wait}}\right)=-\frac{1}{2} \cdot \delta \cdot \mathrm{H}_{\mathrm{j}}+\frac{1}{2} \cdot \delta \cdot \frac{\mathrm{e}+\varepsilon-\mathrm{w} \cdot \mathrm{a}_{\mathrm{j}}}{1-\delta} ; \quad \mathrm{E}_{\mathrm{t}}\left(\mathrm{V}_{\mathrm{j}, \mathrm{t}}^{\mathrm{entry}}\right)=-\mathrm{H}_{\mathrm{j}}+\frac{\mathrm{e}-\mathrm{w} \cdot \mathrm{a}_{\mathrm{j}}}{1-\delta} .
$$

The option value of having the flexibility to make the employment decision in the next period rather than to employ either now or never, can easily be calculated as the difference between the two expected net present values: $\mathrm{OV}(\mathrm{e}, \varepsilon)=\mathrm{E}_{\mathrm{t}}\left(\mathrm{V}_{\mathrm{j}, \mathrm{t}}^{\mathrm{wait}}\right)-\mathrm{E}_{\mathrm{t}}\left(\mathrm{V}_{\mathrm{j}, \mathrm{t}}^{\mathrm{entry}}\right)$, with: $\partial \mathrm{OV} / \partial \mathrm{e}<0$, $\partial \mathrm{OV} / \partial \varepsilon>0$. (An analogous logic can be applied to the disinvestment/firing put option case.) An increase in uncertainty enlarges the value of the option to employ later. The reason is that it enlarges the potential payoff of the option, leaving the downside payoff unchanged, since the firm will not exercise the option if the exchange rate falls. The firm is indifferent between entry in $\mathrm{t}$ and wait-and-see if $\mathrm{E}_{\mathrm{t}}\left(\mathrm{V}_{\mathrm{j}, \mathrm{t}}^{\mathrm{entry}}\right)=\mathrm{E}_{\mathrm{t}}\left(\mathrm{V}_{\mathrm{j}, \mathrm{t}}^{\text {wait }}\right)$, i.e. if $\mathrm{OV}=0$. The entry-trigger under uncertainty follows as (entry for $\left.e_{t}>e_{j, \text { entry }}^{u}\right)$ :

$$
\mathrm{e}_{\mathrm{j}, \text { entry }}^{\mathrm{u}}=\mathrm{w} \cdot \mathrm{a}_{\mathrm{j}}+(1-\delta) \cdot \mathrm{H}_{\mathrm{j}}+\frac{\delta \cdot \varepsilon}{2-\delta}=\mathrm{e}_{\mathrm{j}, \text { entry }}^{\mathrm{c}}+\frac{\delta \cdot \varepsilon}{2-\delta}=\mathrm{e}_{\mathrm{j}, \text { entry }}^{\mathrm{c}}+\frac{\varepsilon}{1+2 \mathrm{i}} \text {. }
$$

The entry (and exit) exchange rate trigger value under uncertainty is additively (subtractively) augmented by the term $\varepsilon /(1+2 \mathrm{i})$. Thus uncertainty leads to an expansion of the band of inaction. . Uncertainty increases the probability that a firm stays active (passive) if the current level of the revenue e has descended (ascended) from a formerly high (low) level that had earlier induced entry (exit). In our specific simple model the expansion of the band of inaction is even linear with respect to $\varepsilon$. Furthermore, in this simple set up the expansion is even independent of any aspects of heterogeneity.

\section{Aggregation to the macro level under uncertainty}

The qualitative property of micro hysteresis, i.e. the entry trigger being larger than the exit trigger, has not changed, when switching to uncertainty. However, the distance between the trigger values has been enlarged for every firm. With this, the aggregation approach described in section 3 can principally be applied to the case of uncertainty as well. We now focus on the 
implications of a switch from certainty to a situation with uncertainty for the shape and the location of the macro hysteresis loop.

Uncertainty leads to an outward shift of the entry and the exit trigger by $\varepsilon /(1+2 i)$. Taking the situation under certainty described by Fig. 3 as a starting point, $\alpha_{j}$ moves to the north, and $\beta_{j}$ slips westward by this amount. Thus, every $\left(\alpha_{j}, \beta_{j}\right)$-combination characterising firm $j$ is projected to the north-west. Hence the orthogonal distance of each point to the $(\alpha=\beta)-45^{\circ}$-line is increased by $\sqrt{2(\varepsilon /(1+2 \mathrm{i}))^{2}}$. However, the non-hysteretic firms with $\mathrm{H}_{\mathrm{j}}, \mathrm{F}_{\mathrm{j}}=0$ (located on the $\alpha=\beta$-line) retain their position even under uncertainty. Expressed graphically, the whole $\mathrm{S}_{\mathrm{t}}^{+}$-block comprising the active firms (and analogously the $\mathrm{S}_{\mathrm{t}}^{-}$-block describing the inactive firms) is shifted. A $\sqrt{2(\varepsilon /(1+2 i))^{2}}$-wide zone above and parallel to the $\alpha=\beta$-line free of firms emerges. ${ }^{17}$ In Fig. 5 the impacts of an introduction of uncertainty to a situation described by Fig. 3 (a) and (b) are illustrated. Obviously, some firms with formerly positive exit rates may be shifted into the negative range. These firms would even bear negative revenues in order not to loose the sunk costs and the option value of waiting. Since in our simple model the unit revenue is expressed by the exchange rate which is expected to be positive, we will neglect the area on the LHS of the ordinate in our further analysis.

17 For reasons of simplicity, in this paper we have neglected the non-trivial problems which may arise when the possibility of a re-entry after an exit in t (respectively a re-exit after an entry in $t$ ) is given. A re-entry or a reexit-behaviour might become optimal if the sunk costs $\left(\mathrm{H}_{\mathrm{j}}\right.$ and $\left.\mathrm{F}_{\mathrm{j}}\right)$ are 'small' compared to the revenue change due to $\varepsilon$. As a consequence, these firms are not shifted by the full amount. This would result in a zone parallel to the $\alpha=\beta$-line which is not completely "depoputated" as derived above. 
Fig. 5: Active firms after the introduction of uncertainty when exchange rate

(a) has risen before

(b) has decreased before
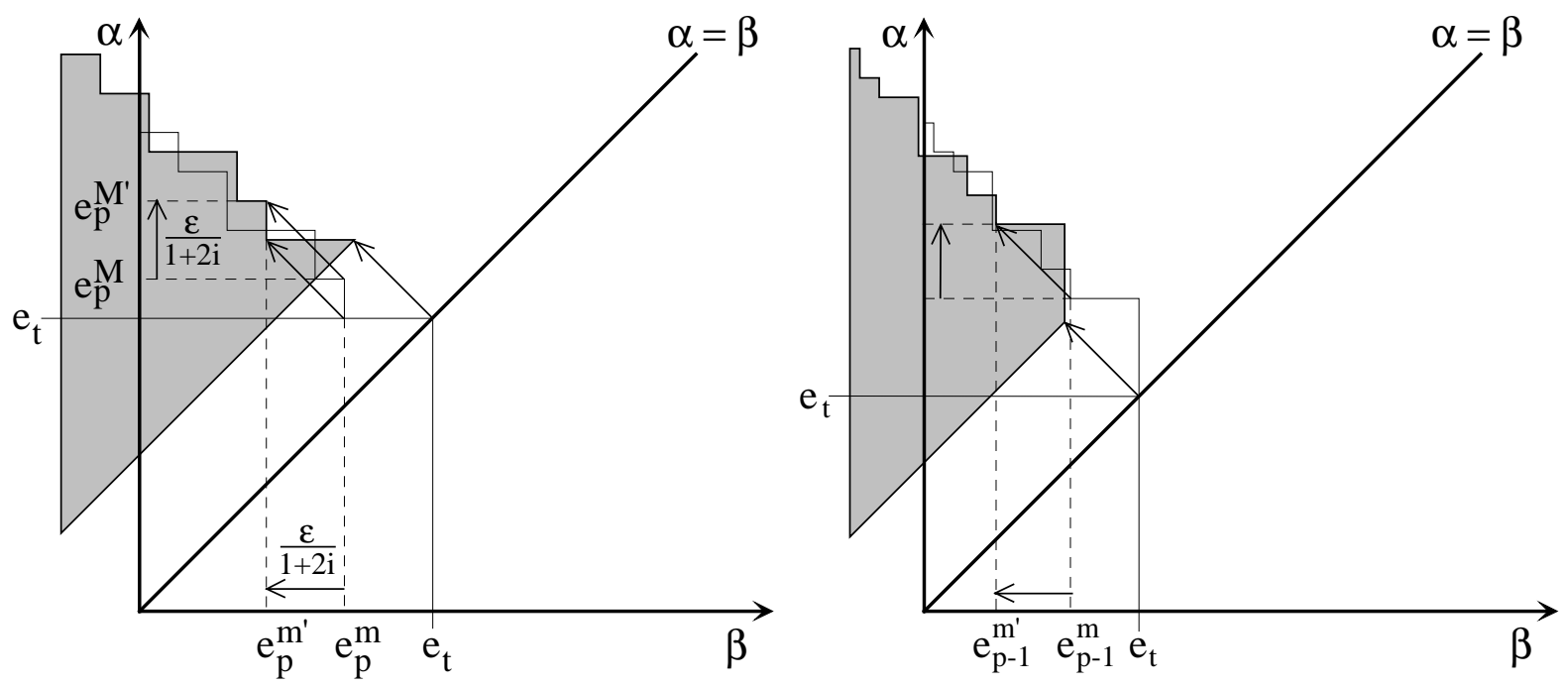

For simplicity reasons, with respect to the certainty situation we assume a preceding time path of the exchange rate which has produced a 'staircase-borderline' with an infinite number of non-erased extrema resulting in infinitesimally small steps, resulting in a $\left(-45^{\circ}\right)$-borderline with a negative slope equal to one. This procedure has the advantage to abstract from the differentiation concerning the actual direction of e underlying the parts (a) and (b) of Fig. 5 leaving the main effects of uncertainty on the aggregation procedure unaffected. All initially active firms are included in the triangle area $\mathrm{S}^{+}$depicted in Fig. 6 (a). The initial exchange rate is given as $\mathrm{e}_{0}$. Introduction of uncertainty results in a north-western shift of $\mathrm{S}^{+}$to the triangle $\mathrm{S}^{+}$as illustrated in Fig. 6 (b).

Taking $\mathrm{e}_{0}$ as initial value, an increase in the exchange rate up to $\mathrm{e}_{1}$ does not affect any 'hysteretic' firm (with $\mathrm{H}_{\mathrm{j}}, \mathrm{F}_{\mathrm{j}}>0$ ) in the shifted triangle $\mathrm{S}^{+}$'. Only 'non-hysteretic' firms (with $\mathrm{H}_{\mathrm{j}}, \mathrm{F}_{\mathrm{j}}=0$ ) on the $\alpha=\beta$-line change from inactivity to activity. Thus, in this 'play' interval an increase in the exchange rate leads only to a weak reaction of employment, as it is depicted in Fig. 7 (as the movement from point A to B). ${ }^{18}$ A further increase e.g. to the local maximum $e_{2}$ induces additional employment corresponding to the area $\sigma_{1}$ in Fig. 6 (b) (point B to C in Fig.

18 For reasons of simplicity, this reaction is depicted in a linear way. I.e. non-hysteretic firms are assumed to be equally distributed on the $\alpha=\beta$-line. 
7). While the initial weak reaction $A B$ shows similarities to mechanical 'play', ${ }^{19}$ the subsequent additional increase BC leads to a strong reaction which can be titled 'spurt' in employment. More concretely, after a reversal of the exchange rate the initially weak response of employment will evolve into a very strong response, once the thresholds of many firms are passed. ${ }^{20} \mathrm{~A}$ reversal of the exchange rate towards $\mathrm{e}_{3}$ will again cause a weak ('play') reaction (CD). A further decrease in the exchange rate to $\mathrm{e}_{4}$ leads to an erasure of the formerly gained employment $\sigma_{1}$ as well as to new unemployment described by the area $\sigma_{2}$. Again a weak 'play'-reaction follows for a subsequent increase to $e_{5}(E F)$. An exchange rate movement $\mathrm{e}_{0} \rightarrow \mathrm{e}_{1} \rightarrow \mathrm{e}_{2} \rightarrow \mathrm{e}_{3} \rightarrow \mathrm{e}_{4} \rightarrow \mathrm{e}_{5}$ will result in a hysteresis loop determined by ABCDEF. In contrast, the corresponding hysteresis loop under certainty (as already described in Fig. 4) is depicted by the dotted path AHKM in Fig. 7.

Fig. 6: Active firms dependent on the exchange rate

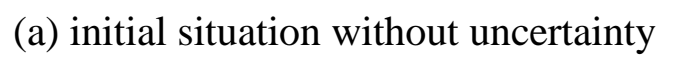

(b) after introduction of uncertainty
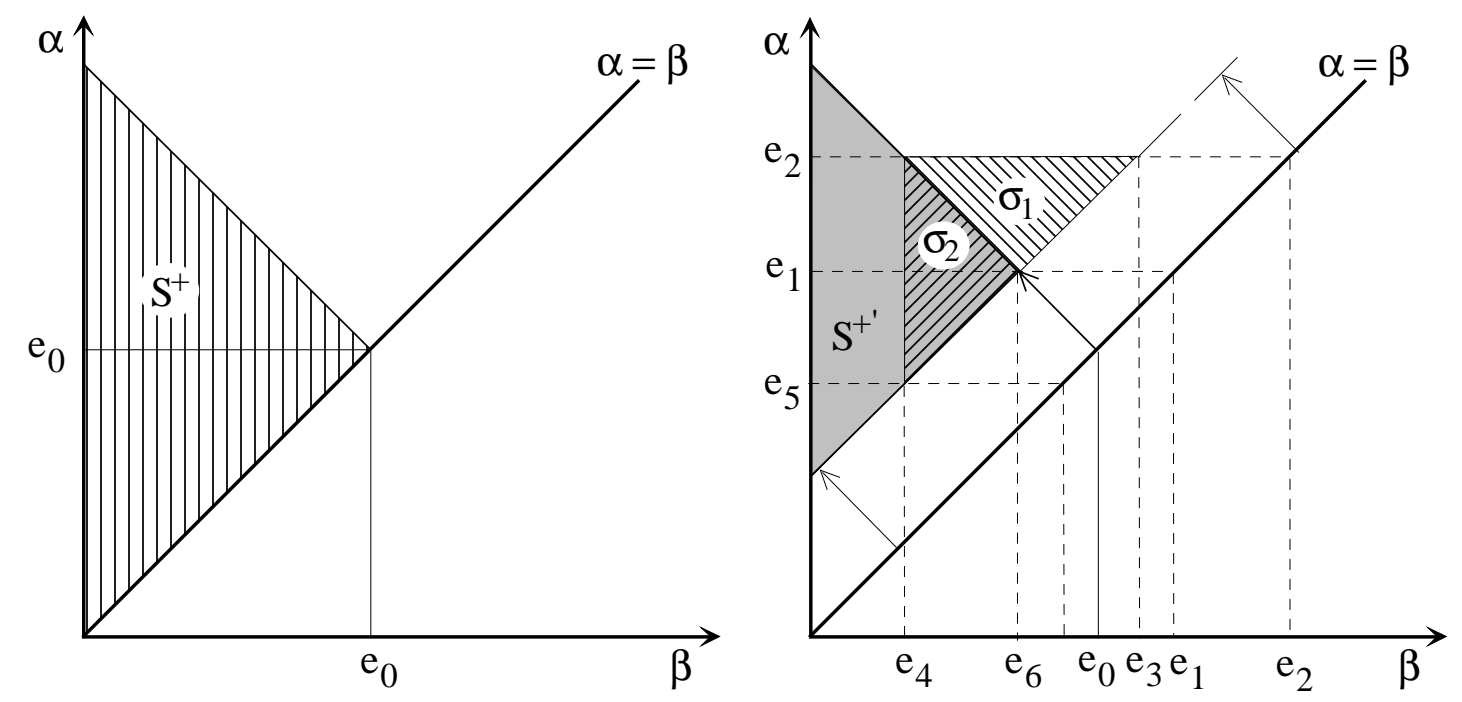

Starting from the initial situation $\left(\mathrm{e}_{0}\right.$ respectively point $\left.\mathrm{A}\right)$ again, now assume a decrease in the exchange rate from $e_{0}$ to $e_{6}$. As before, a 'play'-reaction results (AG). A further decrease towards $\mathrm{e}_{4}$ analogously leads to a 'spurt' in unemployment described by $\sigma_{2}(\mathrm{GE})$.

19 For a description of original play hysteresis, see Krasnosel'skii and Pokrovskii (1989), pp. 6 ff., and Brokate and Sprekels (1996), pp. 24 f. and pp. $42 \mathrm{ff}$.

20 For a non-formal description of 'spurts' in investment or in employment based on a microeconomic sunk cost mechanism under uncertainty see Pindyck (1988), pp. 980 f., and Belke and Göcke (2001a). Dixit and Pindyck (1994), pp. 15 f., vividly illustrate the non-linear reaction of US-employment after recovery in the mid 1993. However, in these contributions no explicit aggregation approach to derive macroeconomic behaviour is applied. 
Fig. 7: Macro hysteresis loop under uncertainty (including 'play')

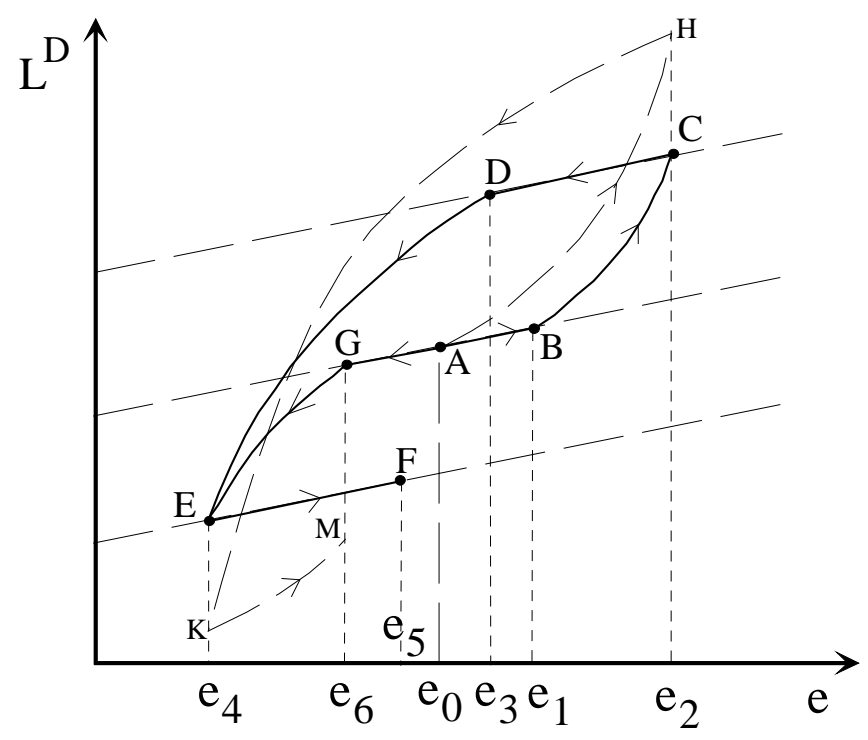

As a main result, the introduction of uncertainty implies additional 'play'-intervals in the macro loop with every reversal of the input direction. The width of the 'play'-interval, i.e. $\left(e_{2}-e_{3}\right),\left(e_{5}-e_{4}\right)$ or $\left(e_{1}-e_{6}\right)$ is given by the same amount: $(2 \varepsilon) /(1+2 \mathrm{i})$. This expression exactly equals the widening effect of uncertainty on the width of the microeconomic 'band of inaction' for the single firm $\left(\mathrm{e}_{\mathrm{j}, \text { entry }}^{\mathrm{u}}-\mathrm{e}_{\mathrm{j}, \text { exiit }}^{\mathrm{u}}\right)$ as implied by eq. (8). ${ }^{21}$ Due to our special initial situation, $\mathrm{e}_{0}$ not being an extremum, the initial play intervals ( $\mathrm{AB}$ or $\mathrm{AG}$ ) amount to the half (i.e.: $\varepsilon /(1+2 \mathrm{i}))$.

The occurrence of 'play'-intervals - implying a weak reaction with every reversal of the input (exchange rate) - results in a weaker reaction of the dependent variable (employment) compared to the situation without uncertainty. This weaker reaction corresponds to the fact that (a) the 'play'-interval has to be passed in order to lead to permanent employment impacts, and (b) a smaller number of firms is affected by exchange rate changes, since all 'hysteretic' firms are shifted to the north-west by uncertainty. These mechanisms finally result in a 'flatter' shape of the hysteresis loop under exchange rate uncertainty.

21 However, this simple and clear result is due to our extremely simple micro model, where the expansion of the band of inaction is linear with respect to uncertainty $\varepsilon$ and even independent of the heterogeneity between firms. But even in a more general formulation the widening of band of inaction will occur due to uncertainty and, thus a kind of a "depopulated" area parallel to the $\alpha=\beta$-line and play-hysteresis will result. 
Our micro model is based on a risk-neutral single-unit (dis)employment decision under revenue uncertainty caused by exchange rate (step) volatility and fixed sunk (i.e. irreversible) hiring and firing costs. It is comparable to models incorporating irreversible investment decisions. However, we do not rely on the asymmetry of adjustment costs (Caballero, 1991) and on scrapping values (Darby et al., 1998), since we analyse 'investments' in employment and not in real capital. In addition, the degree of competition in the output market and economies of scale (Caballero, 1991) do not play a predominant role since we analyse a single-unit decision.

However, at the price of the advantage of being very simple, our model shows limitations due to its partial equilibrium nature. In our model a firm only has the choice between export activity or to stop production at all. In this paper we do not consider the variety of further options a real world firm would have in a situation with an unfavourable and uncertain exchange rate. For example, the firm may have the option to reallocate its labour force from the production of exports to the production for the domestic market. Furthermore, a firm may have the option to internationally reallocate production via direct foreign investments in response to an appreciation of the domestic currency. The consideration of all these options lowers the importance of the non-linear persistent exchange rate effects in foreign trade on aggregate employment. Consequently, our approach may exaggerate the importance of exchange rate variability on aggregate employment.

In an extreme case with a perfect mobility of factors between the production of exports and the production for the domestic market - i.e. if the reallocation of factors is possible without generating any frictional costs - the loop in Fig. 7 would merely describe the distribution of a given supply of labour between both, the production of exports and the production for the domestic market. In such a situation we would have no effects of exchange rate changes on aggregate employment at all. However, in reality we do have costs of reallocation. E.g. selling an increased production on the domestic market may only be possible via cutting prices, and thus is not a profitable option for many firms. Furthermore, producing more goods specific for the domestic market may require specific skills and specific equipment. Training of new skill and establishing specific equipment may again result in sunk costs (of reallocating factors in 
an uncertain environment). Consequently, if we consider realistic imperfections concerning the reallocation of labour, e.g. due to limited intersectoral labour mobility and due to factor specifity, our intuition of exchange rate uncertainty effects on aggregate labour demand qualitatively may even hold in a more general context, however in a quantitatively reduced manner.

Of course, our theoretical results concerning macroeconomic play-areas as a consequence of sunk cost and uncertainty on a microeconomic level deserve an empirical evaluation with tight testable propositions concerning the relation between the exchange rate and aggregate employment. According to the theory developed in this paper, under uncertainty 'play'-areas of weak reactions of aggregate employment on exchange rate changes have to be considered at the macro level. When changes go beyond the play-area a sudden switch to a strong reaction ('spurt') occurs. Moreover, the width of the play-area is a positive function of the degree of uncertainty. Thus we have three testable implications: (1) after a reversal of the direction of the exchange rate path we expect to observe play-areas with a weak or even no effect of exchange rate changes and (2) a switch to a strong reaction of aggregate employment, i.e. structural breaks, if large exchange rate changes occur, and (3) a positive effect of the exchange rate variability on the width of the play-area.

In order to check how well the model is validated by the data, Belke and Göcke (2001) apply a linear approximation of the loop depicted in Fig. 7 in order to approximate the play-shape of the relationship between exchange rate and employment. They develop an estimation algorithm based on a switching-regression approach and find empirical support for playeffects on West-German employment caused by real exchange rate variability. Based on an estimation of their switching-regression model (with quarterly observations from 1973:3 to 1996:1) they show that the non-linear model including play displays a significantly better performance than a standard linear regression model. They estimate play areas without any employment effects in response to exchange rate changes, if these changes are lower than about 10 percent (in case of an average degree of exchange rate uncertainty). Moreover, they find strong support for strong reactions ('spurts') if the magnitude of changes goes beyond 
these play-areas. Furthermore, the estimation reveals a strong impact of exchange rate variation (measured as the standard deviation over the preceding twelve months) on the size of the play areas. Thus, all three theoretical implications concerning the dynamics of aggregate labour demand are corroborated by this first attempt of an empirical validation.

\section{Conclusion}

In this contribution, non-linearities in the relation between total economy employment and the exchange rate are emphasised. A potential mechanism based on a band of inaction that is induced by sunk costs and could account for a 'weaker' relationship between employment and its determinants has been augmented by exchange rate uncertainty. As a result of option value effects the band of inaction is widened and, thus, hysteresis effects are strongly amplified by uncertainty. Special attention has been paid to the problem of aggregation under uncertainty. It has been shown that under uncertainty 'play'-areas have to be considered at the macro level. Thus, similarities of macro relations ['play'] to micro behaviour [band of inaction] are enhanced by uncertainty. ${ }^{22}$

We ascribe the revenue volatility to exchange rate volatility. However, since uncertainty effects on the revenue $\varepsilon$ is additively included in the revenue function, an interpretation of $\varepsilon$ as an all comprising expression of uncertainty in exchange rates, foreign prices, wages and productivity is straightforward. Moreover, the relation between employment and all its driving forces (e.g. the wages) is affected by uncertainty. We focus on the calculation of exchange rate triggers, holding other determinants of employment constant. Similarly, one could calculate trigger values for, e.g., wages resulting in a band of inaction concerning wages. An application of our aggregation approach based on wages is straightforward. According to our results, due to uncertainty, total economy employment is expected to be less sensitive than previously expected to movements in the exchange rate, foreign prices, wages and productivity.

22 Thus, additional empirical studies in the manner of Parsley and Wei (1993) introducing uncertainty related zones of inaction may be adequate even on the macro level. 
Moreover, our findings may be of a more general interest, since the aggregation mechanisms detected here may apply to other cases where the aggregation of microeconomic real option effects under uncertainty becomes necessary.

\section{References}

Amable, B., Henry, J., Lordon, F. and R. Topol (1991), 'Strong Hysteresis: An Application to Foreign Trade', OFCE Working Paper / Document de travail 9103, Observatoire Français des Conjonctures Economiques, Paris.

Amable, B., Henry, J., Lordon, F. and R. Topol (1994), 'Strong Hysteresis versus Zero-Root Dynamics', Economic Letters 44, 43-47.

Amable, B., Henry, J., Lordon, F. and R. Topol (1995), 'Weak and Strong Hysteresis: An Application to Foreign Trade', Economic Notes 24, 353-374.

Baldwin, R. and P. Krugman (1989), 'Persistent Trade Effects of Large Exchange Rate Shocks', Quarterly Journal of Economics 104, 635-654.

Belke, A. and M. Göcke (1999), 'A Simple Model of Hysteresis in Employment under Exchange Rate Uncertainty', Scottish Journal of Political Economy 46, 260-286.

Belke, A. and M. Göcke (2001), 'Exchange Rate Uncertainty and Employment: An Algorithm Describing "Play" ', Applied Stochastic Models in Business and Industry 17/2, 181-204.

Belke, A. and M. Göcke (2001a), 'Exchange Rate Uncertainty and 'Play'-Nonlinearity in Aggregate Employment', International Advances in Economic Research 7, 38-50.

Belke, A. and D. Gros (2001), 'Evidence on the Costs of Intra-European Exchange Rate Variability', Open Economies Review 12, 231-264.

Bentolila, S. and G. Bertola (1990), 'Firing Costs and Labour Demand: How Bad is Eurosclerosis?', Review of Economic Studies 57, 381-402.

Brokate, M. and J. Sprekels (1996), 'Hysteresis and Phase Transitions', in: Marsden, J.E, Sirovich, L., John, F. (eds.), Applied Mathematical Sciences 121, Springer, New York.

Caballero, R. J. (1991), 'On the Sign of the Investment-Uncertainty Relationship', American Economic Review 81, 279-288.

Caballero, R.J., Engel, E.M.R.A. and J. Haltiwanger (1997), 'Aggregate Employment Dynamics: Building from Macro Evidence', American Economic Review 87, 115-137.

Côté, A. (1994), 'Exchange Rate Volatility and Trade - A Survey', Bank of Canada, Working Paper 94-5, Ottawa.

Cross, R. (1994), 'The Macroeconomic Consequences of Discontinuous Adjustment: Selective Memory of Non-Dominated Extrema', Scottish Journal of Political Economy 41, 212-221.

Cushman, D. (1985), 'Real Exchange Rate Risk, Expectations, and the Level of Direct Investment', Review of Economics and Statistics 67, 297-308. 
Darby, J., Hughes Hallet, A., Ireland, J. and L. Piscitelli (1998), 'The Impact of Exchange Rate Uncertainty on the Level of Investment', CEPR Discussion Paper 1896.

De Grauwe, P. and F. Skudelny (1997), 'The Impact of EMU on Trade Flows', Katholieke Universiteit Leuven, Department of Economics Discussion Paper 133.

Dixit, A. (1989), 'Entry and Exit Decisions under Uncertainty', Journal of Political Economy 97, 620638.

Dixit, A. and R.S. Pindyck (1994), Investment under Uncertainty, Princeton, NY.

Dornbusch, R. (1987), 'Open Economy Macroeconomics: New Directions', NBER Working Paper 2372.

Göcke, M. (1994), 'Micro- and Macro-Hysteresis in Foreign Trade', Aussenwirtschaft Schweizerische Zeitschrift für internationale Wirtschaftsbeziehungen 49, 555-578.

Göcke, M. (2002), 'Various Concepts of Hysteresis applied in Economics', Journal of Economic Surveys 16/2, 167-188.

Krasnosel'skii, M.A. and A.V.Pokrovskii (1989), Systems with Hysteresis, Springer, Berlin.

Krugman, P. (1989), Exchange Rate Instability, MIT Press, Cambridge/MA.

Mayergoyz, I.D. (1986), 'Mathematical Models of Hysteresis', IEEE Transactions on Magnetics 22, 603-608.

Parsley, D.C. and S.-J. Wei (1993), 'Insignificant and Inconsequential Hysteresis: the Case of U.S. Bilateral Trade', Review of Economics and Statistics 75, 606-613.

Pindyck, R.S. (1988), 'Irreversible Investment, Capacity Choice and Uncertainty', American Economic Review 78, 969-985.

Pindyck, R.S. (1991), 'Irreversibility, Uncertainty, and Investment', Journal of Economic Literature 29, 1110-1148.

Piscitelli, L., Cross, R., Grinfeld, M. and H. Lambda (2000), 'A Test for Strong Hysteresis', Computational Economics 15, 59-78.

Saint-Paul, G. (1996), Dual Labor Markets: A Macroeconomic Perspective, MIT Press, Cambridge/MA.

van Garderen, K.J., Lee, K. and M.H. Pesaran (1997), 'Cross-Sectional Aggregation of Non-Linear Models', DAE Working Paper 9803, University of Cambridge - Department of Applied Economics. 